\title{
Who makes the decisions?
}

Patient "compliance" in modern medicine

\begin{tabular}{|c|c|c|}
\hline $\begin{array}{l}\text { Traditionally, the term "patient } \\
\text { compliance" was used to } \\
\text { define how closely a patient } \\
\text { followed their doctor's advice. } \\
\text { Now, with the ever-expanding } \\
\text { information and resources } \\
\text { available to patients, the idea } \\
\text { of "compliance" is in need of an } \\
\text { update. Professor Karen Lutfey } \\
\text { Spencer, of the University of } \\
\text { Colorado Denver, USA, looked } \\
\text { at the experiences of patients } \\
\text { receiving end-of-life care to gain } \\
\text { an insight into their decision- } \\
\text { making processes. This research } \\
\text { increases understanding of } \\
\text { how and why patients make } \\
\text { their decisions, and why some } \\
\text { choose not to follow their } \\
\text { doctor's recommendations. }\end{array}$ & 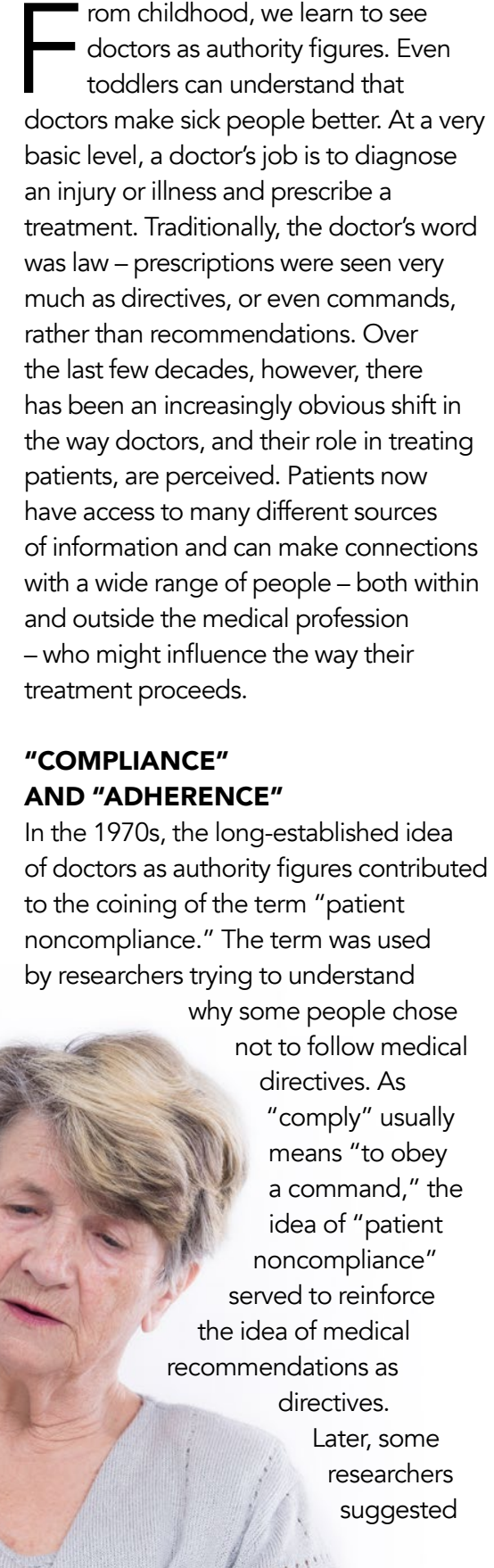 & $\begin{array}{l}\text { that "adherence" should be used } \\
\text { instead, as it better suited the goal of } \\
\text { patients being partners in their treatment. } \\
\text { However, research still tended to focus } \\
\text { on how the behaviour of patients could } \\
\text { be changed to better match the advice } \\
\text { of the medical system. } \\
\text { Much has changed in the field of medical } \\
\text { care in the decades since the terms } \\
\text { "compliance" and "adherence" were first } \\
\text { used. Options for medical treatment have } \\
\text { expanded dramatically with advances } \\
\text { in science. At the same time, the ways in } \\
\text { which patients access medical care, arrive } \\
\text { at a treatment plan and choose whether } \\
\text { to follow medical recommendations have } \\
\text { proliferated. For example, the internet } \\
\text { plays a huge role in many people's } \\
\text { lives. For those recently diagnosed } \\
\text { with an illness, it is an almost infinite } \\
\text { source of information of highly variable } \\
\text { quality. Patients can do everything from } \\
\text { reading medical journal articles to joining } \\
\text { social media support groups. Personal } \\
\text { relationships - with friends, relatives, } \\
\text { colleagues or religious leaders, for } \\
\text { example - can also influence a person's } \\
\text { medical choices. All of these factors can } \\
\text { influence the decisions a person makes, } \\
\text { both at the time of diagnosis and at } \\
\text { any point along their treatment pathway. } \\
\text { For patients, the decision-making process } \\
\text { is clearly potentially complex and the } \\
\text { role of physicians is becoming less clear } \\
\text { over time. For this reason, Professor } \\
\text { Spencer believes that it is time to update } \\
\text { the ideas of compliance and adherence. } \\
\text { By focussing on the myriad ways in } \\
\text { which people engage with medical care } \\
\text { today, researchers will be able to better } \\
\text { understand why some patients choose } \\
\text { not to follow medical recommendations. }\end{array}$ \\
\hline
\end{tabular}

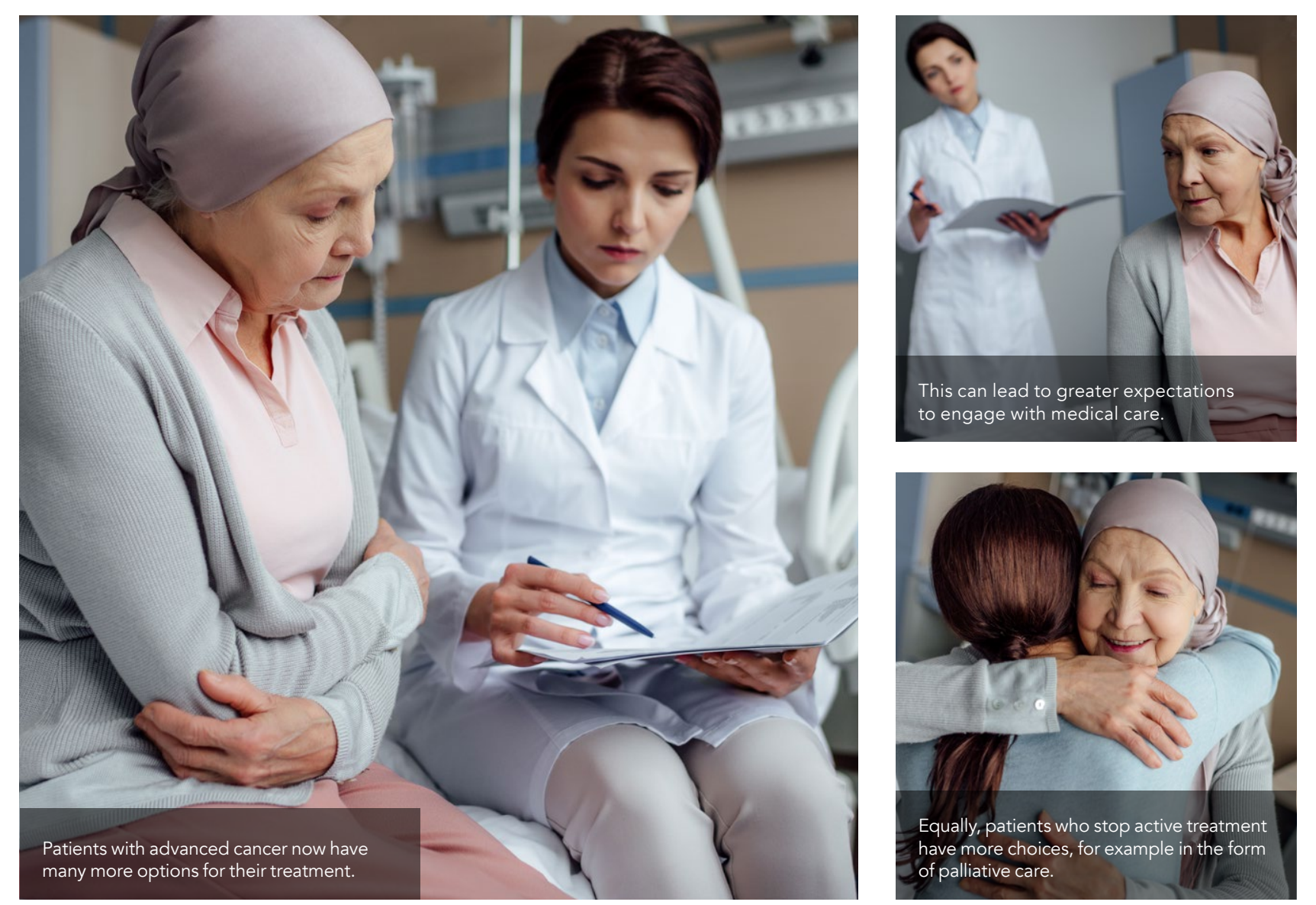

END-OF-LIFE DECISIONS Decisions on medical treatment carry a special weight when a patient is facing a terminal diagnosis. There might be a choice between continuing active treatment (i.e., treatment that attempts to cure or control an illness) or moving to palliative care (which aims to improve quality of life), for example. Every patient will have a unique set of reasons tor making their own particular choices. abou how exctly a person's condition will progress. This makes end-of-life care a very useful situation for looking at patient compliance.

Professor Spencer is based in the US, where there is evidence that many terminal patients do not receive their preferred choice of end-of-life care. The situation is improving - the number of hospitals with palliative care teams has increased dramatically since 2000 - yet there still seems to be a mismatch between the care that is, or should be, avaliable, and the care that patients receive.

Professor Spencer conducted a study about the decision-making

The ways patients access medical care, arrive at a treatment plan and choose whether to follow medical recommendations have proliferated. processes of patients receiving end-of-life care through in-depth, research assistant, Professor Spencer interviewed 26 patients, 16 caregivers, and 32 healthcare providers. Most of the patients were at a stage of their treatment where they were deciding whether or not to continue with active treatment. The patients were aged 50 or older, and around threequarters had some form of cancer.

THE MODERN PATIENT Compared to, say, forty years ago, a patient with advanced cancer has many more options for their treatment. Clearly, this is a positive thing. Professor Spencer notes, however, that more options often with medical care. Yet, at the same time, more choices, in the form of palliative lead to greater expectations to engage care, hospice services and, in some US states, medical aid-in-dying.

This diversity of options was reflected in the choices made by the patients the treatment route chosen, and the reasons for taking that path, varied greatly from person to person. Some patients sought a second opinion or turned to the scientific literature, while others were influenced by their relationship with their doctors, their religious beliefs, or their family or social networks. For example, one patient, on learning that her cancer had returned, in touch with a palliative care team.

While their decision-making pathways were different, something many of contacted the head of her ovarian cancer support group, who then put her 


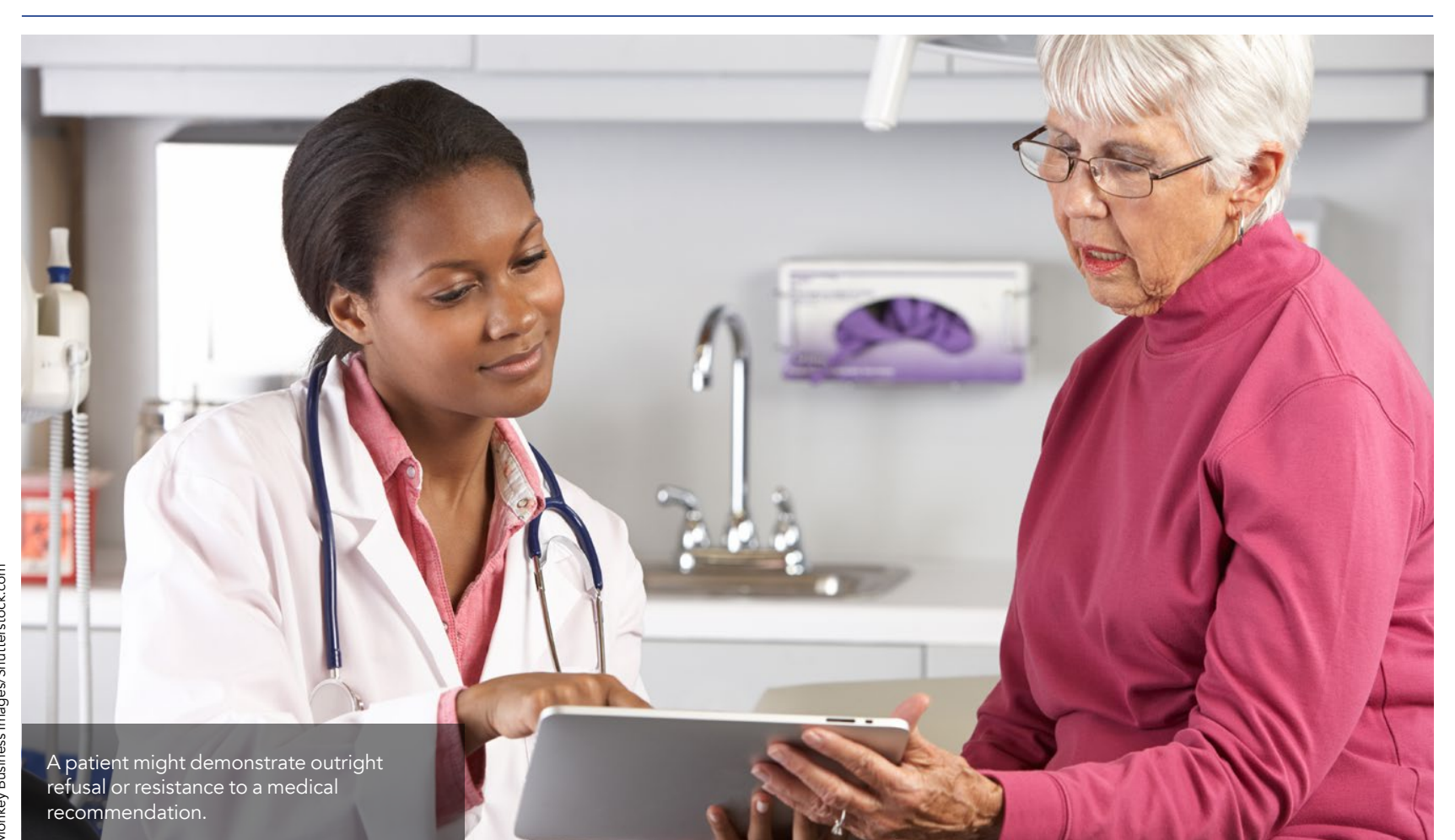

they used multiple different sources of information, accessed a variety expertise in navigating their treatment.

\section{CARE PATHWAYS}

Professor Spencer's research highlights that the way a patient's care pathway develops - whether they choose to follow their physician's advice, or not - may be more important than the single factor$$
\text { of "compliance." }
$$

In fact, "noncompliance" may be too simplistic term. A patient might refusal or resistance to medical recommendation but they could also express dissatisfaction in more subtle ways. For example, one patient chose to switch from a hospital to a local medical centre because he felt that he was being "experimented on" at the hospital. A different patient, a woman with breast cancer, resisted the treatment plan suggested by her oncologist, instead entirely reshaping her treatment towards a palliative care route.

One patient, who said that he had had outright disagreements with his "It's your body Nobody feelings: "It's your body. Nobody knows your
body any better than you. Not your husband, not your mother, not your you go through. Your aches and your pains. Your digestion problems Your bowel movement problems. The whole thing..."

These cases neatly demonstrate that it is the patient - not necessarily the doctor - who is central to the way treatment proceeds. Even patients

the Internet, watching TV, reading books. So, I've still got that."

IS "COMPLIANCE" STILL USEFUL? The insight offered by these patients allowed Professor Spencer to reach a conclusion: that compliance is still There are cer but with qualifications. of medical care where the authority of and patient choice is necessarily limited for example, emergency

Compliance can be difficult to situations, or post-surgical define, because there may be complications. However, several different, but equally more ambiguous, as is valid, options.

make choices that result in very different out of a collaboristions often between patien care pathways. This was illustrated by two and doctor. "Compliance" can be patients who both expressed a strong difficult to define, because there may that her beliefs meant that she should options. Professor Spencer suggests continue treatment - and, in fact, could that future research should look at both not envisage a situation where she would reject further treatment - the second patient reached the opposite conclusion choosing not to pursue active treatmen Finally, one patient, on facing a terminal diagnosis, simply chose to prioritise the parts of his life he enjoyed, saying,

how patients make decisions and why

they make the choices they do: which

sources of information do they turn doctor's recommendations, or other parts of their lives? All aspects of decisionfit with the ree is to be updated to better religious belief. However, while one felt be several different, but equally valid, making are relevant if the idea the doctor is and should be paramount

\section{- Behind the Research} Dr Karen Lutfey Spencer

: karen.spencer@ucdenver.edu T: +1 3033157156 W: https://clas.ucdenver.edu/hbsc/karen-lutfey-spencer

\section{Research Objectives}

Dr Spencer examines end-of-life care choices to explore how compliance and adherence look today.

\section{Detail}

Karen Lutfey Spencer do Denver

PO Box 173364

Denver, CO 80217-3364

Bio

Karen Lutfey Spencer is a medical sociologist with research interests in clinical decision making, patient-provider relationships, and health disparities, studied from both qualitative and quantitative perspectives and across conditions such as diabetes, coronary heart disease, schizophrenia, and depression. Her current work is focused on the social context of end-of-life decision making

Funding

Colorado Denver If University of Colorado

to, and why? Do they prioritise their
Department of Health and Behavioral Sciences

\section{References}

Spencer, KL. 2018. Transforming Patient Compliance Research in an Era of Biomedicalization. Journal of Health and Social Behavior 59(2):170-184. Cross-Domain Influences on Medical Decision Making and the Importance of Social Context for Understanding Barriers to Hospice Use." Journal of Applied Social Science 11(1):48-59.

\section{Personal Response}

How do you think patient "compliance" or "noncompliance" could be defined, going forwards? Oris there a bettertem?

II The terms are secondary to the concepts underlying
them. For example, we can substitute the term "adherence" them. For example, we can substitute the term "adherence" which implies that patients are partners with providers,
However if adherence is conceptualised only in terms However, if adherence is conceptualised only in terms
of whether a patient follows medical recommendations then we lose sight of other matters in life that person may prioritise over medical authority. By doing that, we overlook the diversity of pathways that people take in their own health management. To understand medical decision
making, there is a need to know how patients prioritise across all domains of life, not just the extent to which they obey physicians.$$
\text { , }
$$

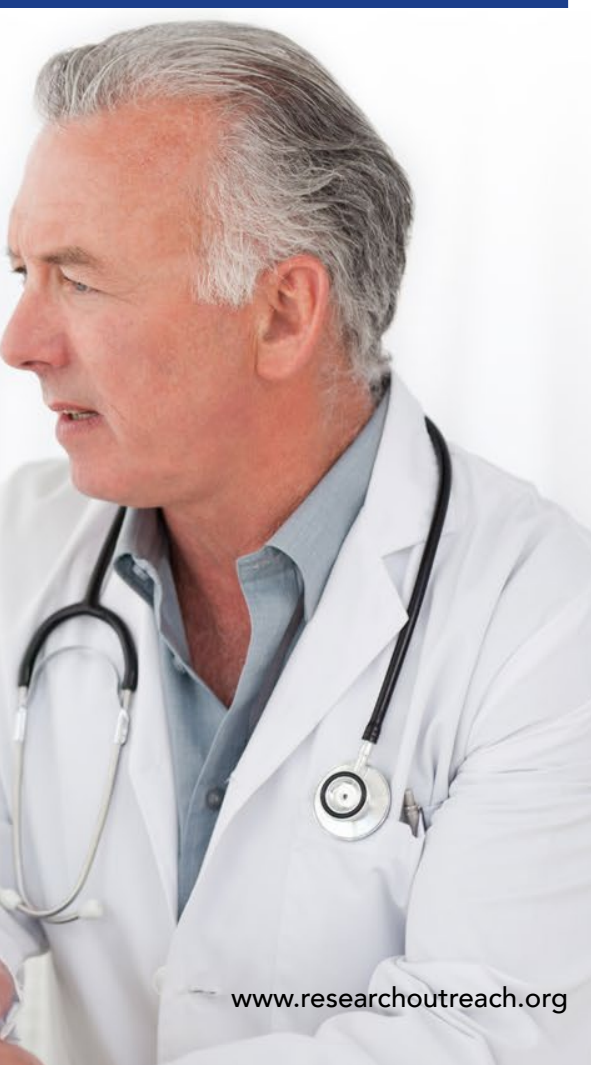

Spencer, Karen Lutfey, Emily Hammad Mrig, Elizabeth Kessler

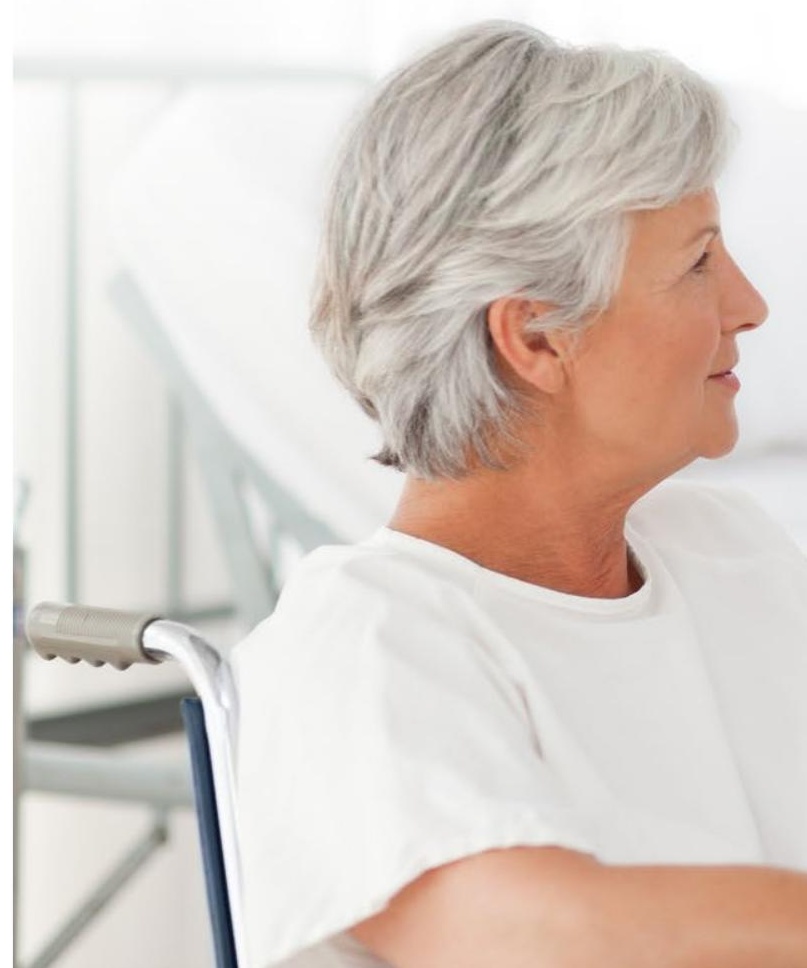

